\title{
Psychological Status and Behavior Changes Among Addis Ababa People during the COVID-19 Epidemic.
}

Fantaye Woldemedihin ( $\sim$ fanytiruneh@gmail.com)

Kotebe Metropolitan University

Reta Anbesse

Kotebe Metropolitan University

Yawukal Kasahun

Kotebe Metropolitan University

Mulualem Melaku

Technology and Innovation Institute

\section{Research Article}

Keywords: COVID-19, Psychological status, Behavior change, Anxiety, Depression, Psychological abnormalities

Posted Date: December 29th, 2020

DOI: https://doi.org/10.21203/rs.3.rs-134839/v1

License: (a) (i) This work is licensed under a Creative Commons Attribution 4.0 International License. Read Full License 


\section{Abstract}

Background: The outbreak of coronavirus disease-19 (COVID-19) is a public health emergency of international concern. The epidemic has brought not only the risk of being infected and death but also unbearable psychological impact like anxiety and depression. The aim of this study was investigating the psychological status and behavior changes of the public during COVID-19 epidemic.

Methods: None randomly selected 300 respondents were recruited voluntarily and completed questionnaire. We used the State-Trait Anxiety Inventory, Selfrating Depression Scale, and Symptom Checklist-90 to evaluate psychological status. We also investigated respondents' behavior changes. Quantitative data were analyzed by t-tests or analysis of variance, and classified data were analyzed with chi-square tests. We just simply describe the qualitative data we got by interviewing medical doctors who are working at referral and designated COVID-19 treatment hospital in Addis Ababa.

Result: More respondents had state anxiety than trait anxiety (46.7\% vs. $30.0 \%)$. Respectively, mild, moderate and severe depression was found among $28.1 \%, 7.2 \%$ and $1.4 \%$ of respondents and $27.4 \%$ had psychological abnormalities. Our analysis of the relationship between subgroup characteristics and psychological status showed that age, occupation, income level, knowledge about COVID-19, Place where the participants' lives and confidence about overcoming the outbreak significantly influenced psychological status. Around $84.1 \%$ of respondents were avoided and significantly reduce going to public places than in previous years and $91.8 \%$ of respondents reduced visiting families, relatives and friends and holyday-related activities during Eastern and Arafa.

Conclusion: COVID-19 not only causes physical health concerns but also results in a number of psychological problems. We need to pay more attention to public psychological stress, especially among young people, as they are likely to experience anxiety, depression, and psychological abnormalities.

\section{Background}

Anxiety is a subjective feeling of apprehension, nervousness, tension, and worry related to the arousal of automatic nervous system. Anxiety can gravely have a negative influence and can inhibit the ability of attentiveness and daily activities (1). Anxiety can manifest itself in two recognizable ways, state or trait. State anxiety is a short-term condition. Patients suffering from trait anxiety usually experience it as a permanent psychological trait (2).

Depression is a mood disorder characterized by a sense of inadequacy, despondency, decreased activity, pessimism, and sadness where these symptoms severely disrupt and adversely affect the person's life, sometimes to such an extent that suicide is attempted or results (3). At its worst, depression can lead to suicide. According to World Health Organization (WHO), depression is a common illness worldwide, with more than 264 million people affected (4).

Severe acute respiratory infection remains one of the leading causes of mortality around the world. The recent pandemic caused by an RNA virus that belongs to the family of CORONA (Latin Crown, from the structure of the virus under electron microscope) virus is a challenge for both developed and underdeveloped nations.

The coronavirus outbreak is a global concern. With each passing day the situation seems to change for the worst. The COVID 19 pandemic is causing huge stress on the health care system of all countries in the world. The impact of the pandemic is both social and economic. It is observed that early interventions with optimal Political commitment and community mobilization help to flatten the curve averting occurrence of many cases and deaths.

In addition to endangering human health and consequently their deaths, COVID-19 imposes irreversible psychological impacts on human societies. For example, complete quarantine and commuting restrictions that prevent people from going out, fear of suffering from the disease, anxiety about losing loved ones, and more importantly, depression following losing friends and family are some of the issues people should deal with (5).

In the absence of appropriate pharmacological interventions, like vaccines or curative drugs, the main method of controlling epidemics like COVID-19 is to change public behavior. An individual's behavior can affect their family, social networks, organizations in which they participate, communities to which they belong, information they obtain, and the impact on their society (6).

Previous experience suggests that the public is likely to experience anxiety, depression, and panic attacks when faced with highly contagious diseases. A study focused on the avian influenza in France $(n=600)$ reported that $39.0 \%$ of participants expressed anxiety about the disease, and $20.0 \%$ that had knowledge about avian influenza had changed their behaviors during the epidemic (7). During the SARS epidemic, a study from Toronto found a high incidence of psychological distress among 129 quarantined individuals. Symptoms of post-traumatic stress disorder and depression were found in 28.9 and $31.2 \%$ of respondents, respectively (8).

During the initial stage of the COVID-19 outbreak, 53.8\% of Chinese respondents rated the psychological impact of the outbreak as moderate or severe, $16.5 \%$ reported moderate to severe depressive symptoms, $28.8 \%$ reported moderate to severe anxiety symptoms, and $8.1 \%$ reported moderate to severe stress levels (9). Similarly, Cuiyan Wang et al. explored the immediate psychological responses and associated factors during the Initial Stage of COVID-19 epidemic among the general population in China and found that $53.8 \%$ of respondents rated the psychological impact of the outbreak as moderate or severe; $16.5 \%$ reported moderate to severe depressive symptoms; $28.8 \%$ reported moderate to severe anxiety symptoms; and $8.1 \%$ reported moderate to severe stress levels (9).

In a study that examined the mental health status and its influencing factors among college students during the epidemic of COVID-19 conducted on 3881 college students in Guangdong Province, china Chang Jinghui, Yuan Yuxin, Wang Dong indicated that the overall incidence of anxiety was $26.60 \%$, and the incidences of mild, moderate and severe anxiety were $23.19 \%, 2.71 \%$, and $0.70 \%$, respectively. Depressive emotions were detected in $21.16 \%$ of the students, 
and the incidences of mild, moderate, and moderate-to-severe depression were $16.98 \%, 3.17 \%$, and $1.01 \%$, respectively (10). Thus, the aim of this review was to assess the psychological status and behavior changes among Addis Ababa people during the COVID-19 epidemic.

\section{Methods}

\section{Research design}

To conduct this research a cross sectional study design was applied to reach at desired objectives. This is because it is designed to study some phenomenon by taking a cross section of it at one time so we will conduct our research through a cross sectional or one shot study.

\section{Source of Data}

The study was carried out based on both primary and secondary data sources. The primary data was collected from people who live in Addis Ababa by using closed ended self-administered questionnaires. We also collect data from 10 medical doctors who are working on COVID-19 response and also we interviewed those medical doctors who provide the routine health service using checklist (Annex 3). The secondary data was collected from different books, journal articles, website, published dissertation papers of the graduates etc.

\section{Data collection technique and instruments}

The study subjects were invited to the study voluntarily by explaining the rationality of the study at the time of data collection. Then standardized selfadministered questionnaire was administered to respondent by trained data collector. Anonymity of the participant was kept by informing them not to write their name and contact.

The questionnaire has four parts. The first part of the questionnaire covered general demographic information, including gender, age, and religion. The second part included questions developed by the present researchers, such as respondents' epidemiological history, their understanding of COVID-19, and the impact of the epidemic outbreak. The third part of the questionnaire comprised the State-Trait Anxiety Inventory (STAl, score range 20-80) designed by Spielberger (11) and the Self-rating Depression Scale (SDS) developed by Zung (12), which were used to evaluate respondents' anxiety and depression, respectively. The final part included the Symptom Checklist-90 (SCL-90) designed by Derogatis (13) which is used to screen for psychological problems other than anxiety and depression. In addition to the above data collection instruments, we used check list to interview the medical doctors who are working in Addis Ababa at different referral and COVID-19 designated hospitals.

\section{Study area}

Ethiopia is divided administratively into nine regional states and two chartered cities, which are further sub-divided in to zones, sub-cities, Woredas (districts) and Kebeles (wards/villages). Addis Ababa is the capital of Ethiopia. It is likewise the biggest city in the nation in terms of population. It is a chartered city and accordingly, is viewed as both a city and a state (14). According to the 2007 census, the city has a population of 2.7 million inhabitants (15). It is located at an altitude of 2000 to $2500 \mathrm{~m}$ above mean sea level. It is where the African Union is headquartered. It also hosts the headquarters of the United Nations Economic Commission for Africa (ECA), as well as various other continental and international organizations. Addis Ababa is therefore often referred to as "the political capital of Africa" for its historical, diplomatic and political significance for the continent (16). The city is divided into 10 boroughs, called subcities, namely Addis Ketema, Akaky kaliti, Arada, Bole, Gillele, Kirkos, Kolfe Keranio, Lideta, Nifas Silk Lafto, and Yeka sub-cities.

\section{Data preparation, presentation and analysis techniques}

Editing and sorting of the questionnaires was done to determine the completeness manually every day. Data entry and analysis was performed by using SPSS for windows version 25. The responses in the completed questionnaire will be coded and entered into a data entry template. Summary tables, figures, and charts were used for describing or presenting analyzed data. The collected data were analyzed using SPSS version 25.0 (IBM SPSS Statistics, New York, United States). Quantitative data were analyzed by t-tests or analysis of variance, and classified data were analyzed by chi-square tests. $\mathrm{P}<0.05$ was considered statistically significant. We just simply describe the qualitative data we got by interviewing medical doctors who are working at referral and designated COVID-19 treatment hospital in Addis Ababa.

\section{Ethical Consideration}

Considering ethical aspect of the research enough time is given to the respondent of the study so that they can depict their true view on research questions. Primary and secondary data was used in this study. The study participants was informed about the benefit of the study as well as there is no risk, Consent from the respondents was taken and appropriate permission was ensure privacy of thier data. Beyond that fact, usage of any secondary data from any source was acknowledged with appropriate reference.

\section{Result}

\section{Respondents' demographic characteristics}

The study period was from July 22, 2020 to August 22, 2020. In total 300 questionnaires were revived; 10 questionnaires were excluded because of a previously diagnosed psychological illness. Among the 290 valid questionnaires included in our study, 13 questionnaires were incomplete. Respondents were from 10 Sub cities around Addis Ababa and were distributed across different ages, occupations, and education levels; therefore, we believe that these respondents could represent the Addis Ababa dwellers. Of all the study participants, 27(9.7\%) were from Nifas Silk Lafto, 26(9.4\%) from Akaki Kaliti, 
29(10.5\%) Addis Ketema, 27(9.7\%) Gulelle, 24(8.7\%) Bole, 30(10.8) Yeka, 30(10.8\%) Arada, 30(10.8\%) Kolife Keraniyo, 26(9.4\%) Kirkos, and 28(10.1\%) were from Lideta sub cities.

Majority of the study participants were male (54.5\%); nearly half of the study participants were belong to the age group 19-39 years (46.2\%) and the rest $27.8 \%, 14.8 \%, 4.3 \%$ and $4.0 \%$ were belong to the age group $40-49,50-59, \leq 18$ and $\geq 70$ years respectively. When we come to the occupation status of the participant, 98(35.4\%) were working in government institutes, 71(25.6\%) were private companies, 55(19.9\%) were self-employed, $27(9.7 \%)$ were students and the rest $24(8.7 \%)$ and $2(1.1 \%)$ were currently unemployed and others like being housewife respectively. With nearly similar proportion $23.1 \%$ were complete secondary school (9-12 grades) and TVET educational level. Participants with college degree and Masters or PhD were $28.9 \%$ and $15.2 \%$ respectively. While, only $4.0 \%$ of the study participants were uneducated. $58.1 \%$ of them were single in their marital status. Majority of the study participants $41.7 \%$ were Orthodox in religion. Relatively, most of the study participants were belongs to the income level 4000 to 6000 birr per month.

Approximately $50 \%$ of the respondents knew much about COVID-19 the current epidemic situation, pathogenesis, transmission routes and preventive measures. $28.9 \%$ of them had some knowledge the transmission route and preventive measures of COVID-19. Similarly, respondent with very much knowledge about pathogen situation, epidemic characteristics, clinical performance, prevention and control measures and epidemic situation were $16.6 \%$. While the rest $5.1 \%$ of the study participants know only about contagious nature of the virus.

Respectively $18.8 \%$ and $23.5 \%$ of the study participants had family members, relatives, friends, colleagues and neighbors who have been diagnosed with COVID-19 or suspected patients and family, relatives, friends, colleagues, neighbors, etc. who are medical staff withstanding COVID-19.

The COVID-19 pandemic is far more than a health crisis: it is affecting societies and economies at their core (18). The study result indicated that, nearly $80.0 \%$ (of which $28.5 \%$ very much) of the participants agreed that the pandemic affect their life and work much. $16.2 \%$ of the participants' life somehow affected by the pandemic. While, $4.0 \%$ of the participants agreed that, the pandemic didn't affect their life. (Figure 5)

Regarding to the confidence that we can overcome the outbreak, $40.8 \%$ of the respondents' had little, $40.8 \%$ had much and 29.6 had very much confidence to overcome the pandemic. While the rest $4.7 \%$ of the participants had no confidence at all regarding to overcoming the outbreak.

Table 1: The demographic characteristics of the respondents 


\begin{tabular}{|c|c|c|}
\hline \multicolumn{2}{|r|}{ Variable } & Number (\%) (Total, $\mathrm{n}=277$ ) \\
\hline \multirow[t]{2}{*}{ Gender } & Male & $151(54.5)$ \\
\hline & Female & $126(45.5)$ \\
\hline \multirow[t]{6}{*}{ Age group (years) } & Below 18 (including 18) & $12(4.3)$ \\
\hline & $19-39$ & $128(46.2)$ \\
\hline & $40-49$ & $77(27.8)$ \\
\hline & $50-59$ & $41(14.8)$ \\
\hline & $60-69$ & $11(4.0)$ \\
\hline & Above 70 (including 70) & $8(2.9)$ \\
\hline \multirow[t]{6}{*}{ Occupation } & Students & $27(9.7)$ \\
\hline & Self employed & $55(19.9)$ \\
\hline & Government employed & $98(35.4)$ \\
\hline & Working In private company & $71(25.6)$ \\
\hline & Unemployed & $24(8.7)$ \\
\hline & Others & $2(1.1)$. \\
\hline \multirow[t]{6}{*}{ Education level } & Uneducated & $11(4.0)$ \\
\hline & Primary school (1-8 grade) & $15(5.4)$ \\
\hline & Secondary school (9-12 grade) & $64(23.1)$ \\
\hline & TVET & $65(23.5)$ \\
\hline & College degree & $80(28.9)$ \\
\hline & Master's or PhD & $42(15.2)$ \\
\hline \multirow{4}{*}{ Marital status } & Single & $161(58.1)$ \\
\hline & Married & 103(37.2) \\
\hline & Divorced & $6(2.2)$ \\
\hline & Widowed & $7(2.5)$ \\
\hline \multirow[t]{4}{*}{ Religion } & Orthodox & $115(41.7)$ \\
\hline & Muslim & $78(28.3)$ \\
\hline & Protestant & $73(26.4)$ \\
\hline & Others & $10(3.6)$ \\
\hline \multirow[t]{6}{*}{ Income level (Birr) } & $<2000$ & $46(18.6)$ \\
\hline & $2000-4000$ & $44(17.8)$ \\
\hline & $4001-6000$ & $48(19.4)$ \\
\hline & $6001-8000$ & $37(15.0)$ \\
\hline & $8001-10000$ & $32(13.0)$ \\
\hline & $>10000$ & $40(16.2)$ \\
\hline \multirow[t]{10}{*}{ Sub city } & Nifas Silk Lafto & $27(9.7)$ \\
\hline & Akaki & $26(9.4)$ \\
\hline & Addis Ketema & $29(10.5)$ \\
\hline & Gulelle & $27(9.7)$ \\
\hline & Bole & $24(8.7)$ \\
\hline & Yeka & $30(10.8)$ \\
\hline & Arada & $30(10.8)$ \\
\hline & Kolife Kraniyo & $30(10.8)$ \\
\hline & Kirkos & $26(9.4)$ \\
\hline & Lideta & $28(10.1)$ \\
\hline \multirow[t]{2}{*}{ Mental Health Problem } & Yes & $10(3.6)$ \\
\hline & No & $267(96.4)$ \\
\hline
\end{tabular}

Note: TVET = Technical and Vocational Education and Training

\section{Public psychological status}

The healthy norm results of the three scales were used as the criteria to assess psychological status. The age range of STAI norm results was 19-69 years; therefore, we excluded 20 questionnaires for respondents aged $<18$ or $>70$ years. According to the healthy norm results of the SDS and SCL-90, depression was classified by an SDS index score $\geq 50$ ( $<50=$ normal, 50-59=Mild, 60-69=Moderate and $\geq 70=$ sever), and the psychological abnormality was classified by a SCL-90 total score $\geq 160$. Respondents' psychological status (state anxiety, trait anxiety, depression, and psychological abnormalities) is shown in Table 2.

Table 2: The proportion of respondents with anxiety, depression and psychological Abnormalities 


\begin{tabular}{|c|c|c|c|}
\hline Variables & & & $\mathrm{n}(\%)$ \\
\hline \multirow{2}{*}{ State anxiety $(n=257)^{a}$} & & Yes & $120(46.7)$ \\
\hline & & No & $137(53.3)$ \\
\hline \multirow{2}{*}{ Trait anxiety $(\mathrm{n}=257)^{\mathrm{a}}$} & & Yes & $77(30.0)$ \\
\hline & & No & $180(70.0)$ \\
\hline \multirow[t]{4}{*}{ Depression $(n=277)$} & Yes & Mild & $79(28.5)$ \\
\hline & & Moderate & $20(7.2)$ \\
\hline & & Severe & $4(1.4)$ \\
\hline & & No & $174(62.8)$ \\
\hline \multirow[t]{2}{*}{ Psychology abnormal (n =277) } & & Yes & $76(27.4)$ \\
\hline & & No & $201(72.6)$ \\
\hline
\end{tabular}

a The age range of ST-AI norm result was from 19 to 69, 20 questionnaires under 18 or above 70 years of age were excluded, 257 cases were enrolled in the analysis

Note: State and trait anxiety cut-off point is $\geq 40$; Depression $($ No $=<50$, mild $=50-59$, moderate $=60-69$ and sever $=\geq 70$ ); cut-off point for psychological abnormality is the total score $\geq 160$.

\section{Proportion of respondents by psychological status}

State anxiety describes the experience of unpleasant feelings when confronted with specific situations, demands or a particular object or event. Trait anxiety describes a personality characteristic rather than a temporary feeling (19). So, the study finding indicated that, More respondents had state anxiety (46.7\%, $120 / 257)$ than trait anxiety $(30.0 \%, 77 / 257)(P<0.001$; Table 3$)$. The average score for state anxiety was also higher than that for trait anxiety $($ Annex Table 1), which remained consistent.

\section{Psychological status by sex and age group}

State anxiety (55.0\%) and trait anxiety (49.4\%) was more common in females than in males. In addition, depression was more common in female [21.0\% (54/257)], of which $32.5 \%$ (41/126) participants had mild, $9.5 \%$ (12/126) moderate and 0.79\% (1/126) severe depression. Relatively more severe depression male participants were observed than female. Respondents' psychological status also differed across age groups. Respondents aged 19-39 years appeared to be more prone to state anxiety (46.7\%), trait anxiety (39.0\%), depression (50.8\%) and psychological abnormalities (31.6\%) than other respondents. Those aged 60-69 years had the lowest rates of state anxiety (7.5\%) and trait anxiety (7.8\%). The proportion of state anxiety and trait anxiety among respondents aged $50-69$ years was $14.2 \%$, and $23.4 \%$ respectively.

Table 3: The chi-square test result between state anxiety and trait anxiety

\begin{tabular}{llccccc}
\hline Variables & & \multicolumn{2}{c}{ Trait anxiety } & \multirow{2}{*}{$\begin{array}{c}\text { Total } \\
\text { n }(\%)\end{array}$} & $X^{2}$ & P value \\
\cline { 3 - 4 } & & Yes & No & & \\
\hline Sate anxiety & Yes & $48(40.0)$ & $72(60.0)$ & $120(46.7)$ & 10.81 & $<0.001$ \\
& No & $29(21.2)$ & $108(78.8)$ & $137(53.3)$ & & \\
\cline { 2 - 5 } & Total & $77(30.0)$ & $180(70.0)$ & 257 & & \\
\hline
\end{tabular}

Table 4: Psychological status of the public under the epidemic of COVID-19 in Addis Ababa 


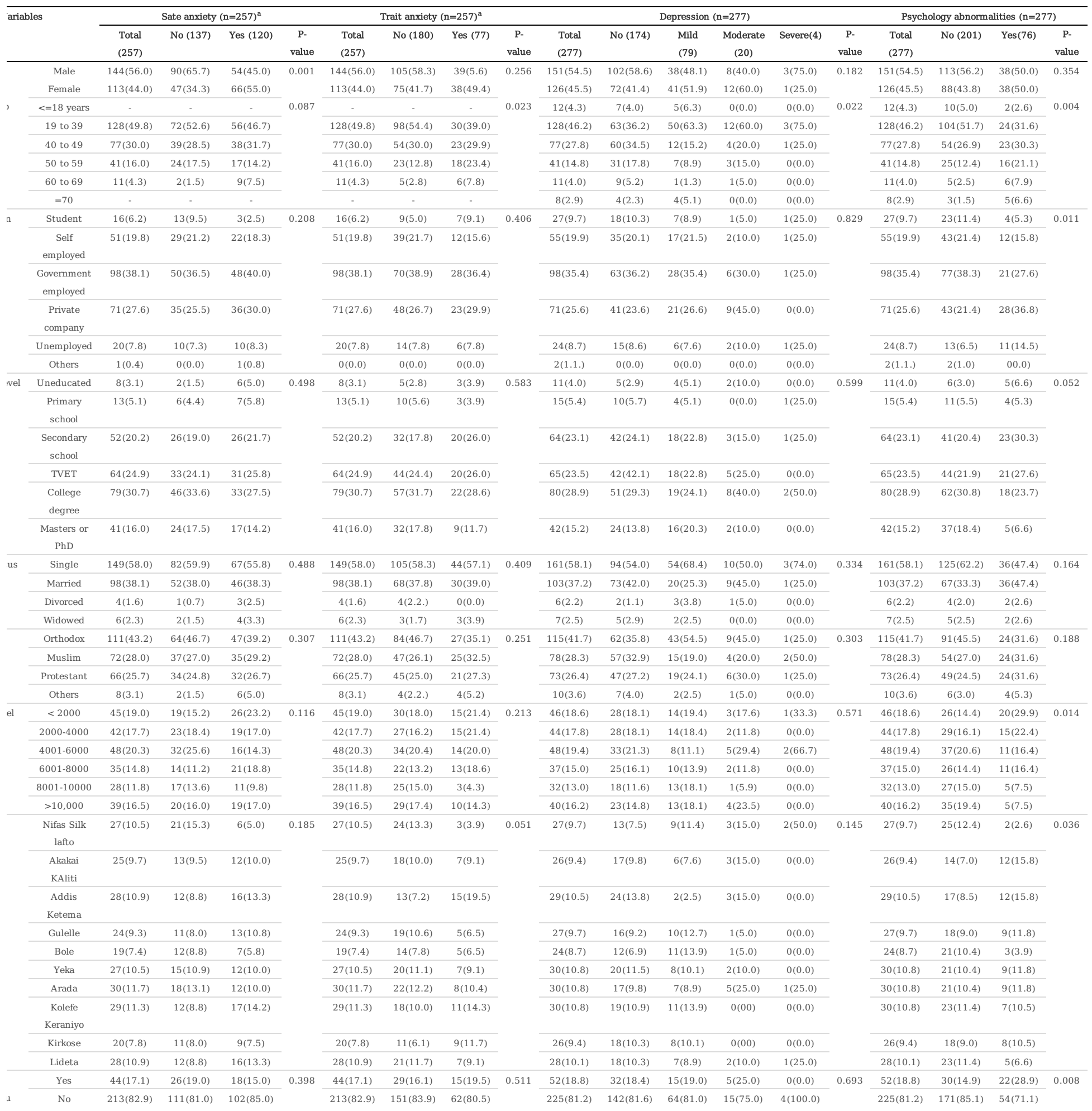

al

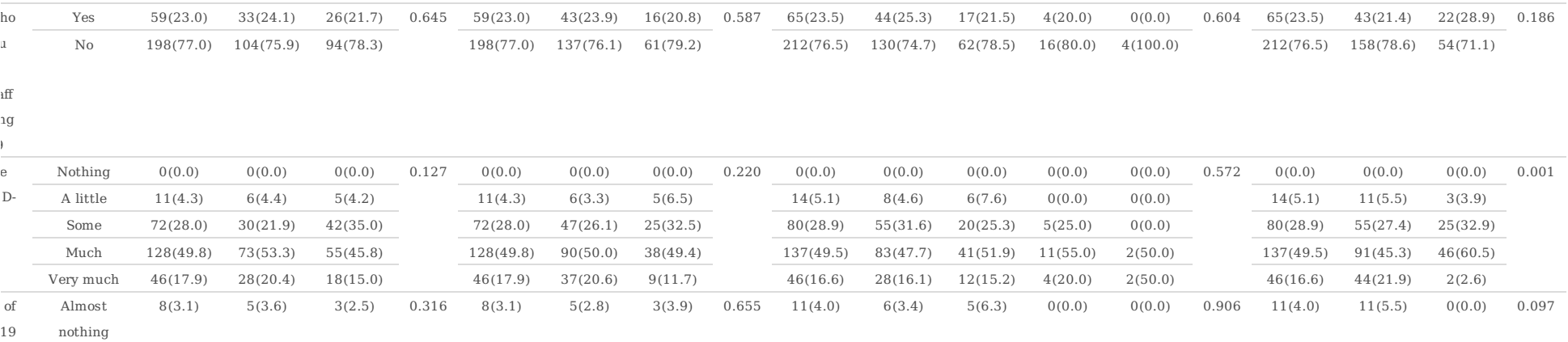




\begin{tabular}{|c|c|c|c|c|c|c|c|c|c|c|c|c|c|c|c|c|c|c|c|}
\hline $\mathrm{n}$ & Some & $40(15.6)$ & $16(11.7)$ & $24(20.0)$ & & $40(15.6)$ & $28(15.6)$ & $12(15.6)$ & & $45(16.2)$ & $30(17.2)$ & 11(13.9) & $3(15.0)$ & $1(25.0)$ & & $45(16.2)$ & $36(17.9)$ & $9(11.8)$ & \\
\hline \multirow[t]{2}{*}{ r } & Much & $134(52.1)$ & $74(54.0)$ & $60(50.0)$ & & $134(52.1)$ & $98(54.4)$ & $36(46.8)$ & & $142(51.3)$ & $90(51.7)$ & $40(50.6)$ & $11(55.0)$ & $1(25.0)$ & & $142(51.3)$ & $99(49.3)$ & $43(56.6)$ & \\
\hline & Very much & $75(29.2)$ & $42(30.7)$ & $33(27.5)$ & & $75(29.2)$ & $49(27.2)$ & $26(33.8)$ & & $79(28.5)$ & $48(27.6)$ & $23(29.1)$ & $6(30.0)$ & $2(50.0)$ & & $79(28.5)$ & $55(27.4)$ & $24(31.6)$ & \\
\hline orry & $\begin{array}{l}\text { Almost } \\
\text { nothing }\end{array}$ & $16(6.2)$ & $10(7.3)$ & $6(5.0)$ & 0.158 & $16(6.2)$ & $8(4.4)$. & $8(10.4)$ & 0.187 & $18(6.5)$ & $13(7.5)$ & $5(6.3)$ & $0(0.0)$ & $0(0.0)$ & 0.446 & $18(6.5)$ & $15(7.5)$ & $3(3.9)$ & 0.060 \\
\hline \multirow[t]{3}{*}{ cal } & Some & $89(34.6)$ & $51(37.2)$ & $38(31.7)$ & & $89(34.6)$ & $66(36.7)$ & $23(29.9)$ & & $98(35.4)$ & $57(32.8)$ & $32(40.5)$ & $6(30.0)$ & $3(75.0)$ & & $98(35.4)$ & $79(39.3)$ & $19(25.0)$ & \\
\hline & Much & $95(37.0)$ & $53(38.7)$ & $42(35.0)$ & & $95(37.0)$ & $69(38.3)$ & $26(33.8)$ & & $104(37.5)$ & $69(39.7)$ & $28(35.4)$ & $7(35.0)$ & $0(0.0)$ & & $104(37.5)$ & $68(33.8)$ & $36(47.4)$ & \\
\hline & Very much & $57(22.2)$ & $23(16.8)$ & $34(28.3)$ & & $57(22.2)$ & $37(20.6)$ & $20(26.0)$ & & $57(20.6)$ & $35(20.1)$ & $14(17.7)$ & $7(35.0)$ & $1(25.0)$ & & $57(20.6)$ & $39(19.4)$ & $18(23)$. & \\
\hline e & $\begin{array}{l}\text { Almost } \\
\text { nothing }\end{array}$ & $12(4.7)$ & $8(5.8)$ & $4(3.3)$ & 0.319 & $12(4.7)$ & $8(4.4)$ & $4(5.2)$ & 0.441 & $13(4.7)$ & $6(3.4)$ & $5(6.3)$ & $2(10.0)$ & $0(0.0)$ & 0.793 & $13(4.7)$ & $8(4.0)$ & $5(6.6)$ & 0.017 \\
\hline g & Some & $110(42.8)$ & $64(46.7)$ & $46(38.3)$ & & $110(42.8)$ & $83(46.1)$ & $27(35.1)$ & & $113(40.8)$ & $73(42.0)$ & $29(36.7)$ & $8(40.0)$ & $3(75.0)$ & & 113(40.8) & $93(46.3)$ & $20(26.3)$ & \\
\hline \multirow[t]{2}{*}{$\mathrm{ak}$} & Much & $62(24.1)$ & $31(22.6)$ & $31(25.8)$ & & $62(24.1)$ & $41(22.8)$ & $21(27.3)$ & & $69(24.9)$ & $43(24.7)$ & $22(27.8)$ & $4(20.0)$ & $0(0.0)$ & & $69(24.9)$ & $43(21.4)$ & $26(34.2)$ & \\
\hline & Very much & $73(28.4)$ & $34(24.8)$ & $39(32.5)$ & & $73(28.4)$ & $48(26.7)$ & $25(32.5)$ & & $82(29.6)$ & $52(29.9)$ & $23(29.1)$ & $6(30.0)$ & $1(25.0)$ & & $82(29.6)$ & $57(28.4)$ & $25(32.9)$ & \\
\hline
\end{tabular}

a The age range of ST-AI norm result was from 19 to 69, 20 questionnaires under 18 or above 70 years of age were excluded, 257 cases were enrolled in the analysis.

Note: The table shows the raw and percentage frequencies of the study participants' psychological status by sex, age group, education level, occupation, marital status, monthly income level, sub-cities and other additional factors. Cut-off values for State and Trait anxiety is $\geq 40$; depression (No depression $<50$; Mild $=50-59$; Moderate $=60-69$; Severe $=\geq 70$ ); psychological abnormality cut-off score is $\geq$ 160 .

Table 5: Chi-square analysis results between behavior changes and different psychological status under the epidemic of COVID-10 in Addis Ababa

\begin{tabular}{|c|c|c|c|c|c|c|c|c|c|c|c|c|c|c|c|c|c|c|}
\hline \multirow[t]{2}{*}{ ables } & \multicolumn{4}{|c|}{ Sate anxiety } & \multicolumn{4}{|c|}{ Trait anxiety } & \multicolumn{6}{|c|}{ Depression } & \multicolumn{4}{|c|}{ Psychology abnormalities } \\
\hline & Total(257) & No(137) & Yes $(120)$ & $\begin{array}{l}\text { P- } \\
\text { value }\end{array}$ & Total(257) & No(180) & Yes(77) & $\begin{array}{l}\text { P- } \\
\text { value }\end{array}$ & Total(277) & No(174) & Mild(79) & Moderate(20) & Sever(4) & $\begin{array}{l}\text { P- } \\
\text { value }\end{array}$ & Total & No & Yes & $\begin{array}{l}\text { P- } \\
\text { value }\end{array}$ \\
\hline Never & $58(22.6)$ & $30(21.9)$ & $28(23.3)$ & 0.465 & $58(22.6)$ & $45(25.0)$ & 13(16.9) & 0.120 & $65(23.5)$ & $42(24.1)$ & $16(20.3)$ & $5(25.0)$ & $2(50.0)$ & 0.903 & $65(23.5)$ & $55(27.4)$ & $10(13.2)$ & 0.006 \\
\hline Sometimes & $158(61.5)$ & $81(59.1)$ & $77(64.2)$ & & $158(61.5)$ & $111(61.7)$ & $47(61.0)$ & & $166(59.9)$ & $106(60.9)$ & $46(58.2)$ & $12(60.0)$ & $2(50.0)$ & & $166(59.9)$ & $121(60.2)$ & $45(59.2)$ & \\
\hline $\begin{array}{l}\text { Same as } \\
\text { usual }\end{array}$ & $40(15.6)$ & $25(18.2)$ & $15(12.5)$ & & $40(15.6)$ & $24(13.3)$ & $16(20.8)$ & & $44(15.9)$ & $25(14.4)$ & $16(20.3)$ & $3(15.0)$ & $0(0.0)$ & & $44(15.9)$ & $24(11.9)$ & $20(26.3)$ & \\
\hline $\begin{array}{l}\text { More than } \\
\text { usual }\end{array}$ & $1(0.4)$ & $1(0.7)$ & $0(0.0)$ & & $1(0.4)$ & $0(0.0)$ & $1(1.3)$ & & $2(0.7)$ & $1(0.6)$ & $1(1.3)$ & $0(0.0)$ & $0(0.0)$ & & $2(0.7)$ & $1(0.5)$ & $1(1.3)$ & \\
\hline Never & $119(46.3)$ & $69(50.4)$ & $50(41.7)$ & 0.345 & $119(46.3)$ & $84(46.7)$ & $35(45.5)$ & 0.093 & $127(45.8)$ & $79(45.4)$ & $40(50.6)$ & $7(35.0)$ & $1(25.0)$ & 0.510 & $127(45.8)$ & $97(48.3)$ & $30(39.5)$ & 0.125 \\
\hline Sometimes & $117(45.5)$ & $60(43.8)$ & $57(47.5)$ & & $117(45.5)$ & $85(47.2)$ & $32(41.6)$ & & $123(44.4)$ & $82(47.1)$ & $28(35.4)$ & $10(50.0)$ & $3(75.0)$ & & $123(44.4)$ & $89(44.3)$ & $34(44.7)$ & \\
\hline $\begin{array}{l}\text { Same as } \\
\text { usual }\end{array}$ & $19(7.4)$ & $7(5.1)$ & $12(10.0)$ & & $19(7.4)$ & $11(6.1)$ & $8(10.4)$ & & $23(8.3)$ & $11(6.3)$ & $9(11.4)$ & $3(15.0)$ & $0(0.0)$ & & $23(8.3)$ & $12(6.0)$ & $11(14.5)$ & \\
\hline $\begin{array}{l}\text { More than } \\
\text { usual }\end{array}$ & $2(0.8)$ & $1(0.7)$ & $1(0.8)$ & & $2(0.8)$ & $0(0.0)$ & $2(2.6)$ & & $2(1.4)$ & $2(1.1)$ & $2(2.5)$ & $0(0.0)$ & $0(0.0)$ & & $4(1.4)$ & $3(1.5)$ & $1(1.3)$ & \\
\hline Stay home & $161(62.6)$ & $86(62.7)$ & $75(62.5)$ & & $161(62.6)$ & $117(65.0)$ & $44(57.1)$ & & $171(61.7)$ & $113(64.9)$ & $41(51.9)$ & $16(80.0)$ & $1(25.0)$ & & $171(61.7)$ & $123(61.2)$ & $48(63.2)$ & \\
\hline $\begin{array}{l}\text { Wearing } \\
\text { face mask }\end{array}$ & $224(87.2)$ & $121(88.3)$ & $103(85.8)$ & & $224(87.2)$ & $158(87.7)$ & $66(85.7)$ & & $236(85.2)$ & $151(86.8)$ & $64(81.0)$ & $17(85.0)$ & $4(100.0)$ & & $236(85.2)$ & $177(88.1)$ & $59(77.6)$ & \\
\hline $\begin{array}{l}\text { Hand } \\
\text { hygiene }\end{array}$ & $204(79.4)$ & $106(77.4)$ & $98(81.6)$ & & $204(79.4)$ & $140(77.7)$ & $64(83.1)$ & & $214(77.3)$ & $136(78.2)$ & $58(73.4)$ & $18(90.0)$ & $2(50.0)$ & & $214(77.3)$ & $154(76.6)$ & $60(78.9)$ & \\
\hline $\begin{array}{l}\text { Take } \\
\text { traditional } \\
\text { medicine }\end{array}$ & $66(25.7)$ & $37(27.0)$ & $29(24.2)$ & & $66(25.7)$ & $42(23.3)$ & $24(31.2)$ & & $70(25.3)$ & $48(27.6)$ & $15(25.9)$ & $6(30.0)$ & $1(25.0)$ & & $70(25.3)$ & $47(23.4)$ & $23(30.3)$ & \\
\hline Others & $20(7.8)$ & $12(8.7)$ & $8(6.6)$ & & $20(7.8)$ & $10(5.5)$ & $10(12.9)$ & & $22(7.9)$ & $18(10.3)$ & $2(2.5)$ & $2(10.0)$ & $0(0.0)$ & & $22(7.9)$ & $13(6.5)$ & $9(11.8)$ & \\
\hline
\end{tabular}

a The age range of ST-AI norm result was from 19 to 69, 20 questionnaires under 18 or above 70 years of age were excluded, 257 cases were enrolled in the analysis.

Note: Cut-off values for State and Trait anxiety is $\geq 40$; depression (No depression $<50$; Mild $=50-59$; Moderate $=60-69$; Severe $=\geq$ 70); psychological abnormality cut-off score is $\geq 160$.

\section{Behavioral change}

From the result, $45.8 \%$ and $44.4 \%$ of participants were never visits and visit their relatives during the holydays significantly less than in previous years respectively. Similarly, $60 \%$ of the study participants, even if they often went to some public places such as supermarkets, church, mosques, parks, sport places and hotels, but less than before outbreak. And also $23.5 \%$ of the study participants didn't go to some public places after the outbreak. But, surprisingly, those who didn't visit their relatives during holydays and went to public places exhibited state and trait anxiety, depression and some other psychological abnormalities (See table 5). 
Participants who went to some public places significantly less than to that of the previous years appeared to be more prone to state anxiety (66.4\%), trait anxiety $(61.0 \%)$ and mild (58.2\%), moderate (60.0\%), and sever (50.0\%) depression. Similarly, $50.2 \%$ of them prone to some psychological abnormalities. Respectively, $41.7 \%, 45.5 \%$ and $50.6 \%$ of the participants who didn't visit their relatives during the holydays had more state anxiety, trait anxiety and mild depression. But those who visited their relatives during the holydays but significantly less than the previous years had relatively high level of moderate (50.0\%) and sever (75.0\%) depression as well as psychological abnormalities (44.7\%).

\section{Influence of other factors on psychological status}

The proportions of respondents with state and trait anxiety, depression and psychological abnormalities differed by their occupation, education level, marital status, and sub-city where the study participants lives. Participants who are working at government institutes had high level state anxiety (40.0\%), trait anxiety (36.4\%), and mild (35.4\%), moderate (30.0\%) and severe (25.0\%) depression. Psychological abnormality was more common among participants who were working at private company (36.8\%).

Participants with college degree has highest rate of state anxiety (27.5\%), trait anxiety (28.6\%) and mild (24.1\%), moderate (40.0\%) and sever (50\%) depression than others, where as participants with secondary school education level more prone to psychological abnormalities. Single participants in their marital status had more state anxiety (55.8\%), trait anxiety (57.1\%) and mild (68.4\%), moderate (50.0\%) and 74.0\%) depression. Respondents' psychological status also differed across the sub-city, location where the participants lives, state anxiety was more common at Kolife Keraniyo sub city [17(14.2\%)] and Lideta sub-city [(16(13.3\%)] and trait anxiety at Addis Ketema sub-city [15(19.5\%)]. Relatively more participants from Bole (13.9\%) and Arada (13.9) sub-city had mild depression. But, relatively large participants from Yeka sub-city exhibited moderate (25.0\%) and severe (25.0\%) depression. Neither the presence of family members, relatives, friends, colleagues and neighbors who have been diagnosed with COVID-19 or suspected patients nor the presence of a medical worker withstanding COVID-19 around respondents increased levels of anxiety, depression and psychological abnormalities.

Moreover, participants whose life or work was affected by COVID-19 outbreak also experience high level of state and trait anxiety, depression and psychological abnormalities. Similarly, those who were more worried about being infected with COVID-19 had a higher proportion of state anxiety, trait anxiety, depression and psychological abnormalities. Of the respondents with state anxiety, trait anxiety, and psychological abnormalities, $35.0 \%$, $33.8 \%$, and $47.4 \%$ were "much worried" about being infected with COVID-19 respectively. Only 5.0\%, 10.4\% and 3.9\% were "not worried at all." Those that were much confident about overcoming the epidemic outbreak appeared to have lower rates of state and trait anxiety and depression compared with other respondents (Table 3).

\section{Other psychological abnormalities}

The SCL-90 is a 90-item self-report symptom inventory designed primarily to reflect the psychological symptom patterns of psychiatric and medical patients. It is a measure of current, point-in-time psychological symptom status, not a measure of personality (20). The SCL-90 covers 10 different psychological abnormality factors. According to the results of the normal model of the scale, we defined a score of $\geq 2$ for each factors as corresponding to abnormal symptoms (6). Based on the study results, which are shown in table 6, majority of the study participants exhibited normal psychological symptoms. But the scores for the Obsessive-compulsive and Interpersonal sensitivity factors were relatively highest with an average score of $1.84 \pm 1.04$ and $1.86 \pm 1.01$ respectively.

Table 6: The results of 277 respondents' SCL-90 factors scores compared with norm result of Chinese healthy (mean \pm std. deviation)

\begin{tabular}{cc}
\hline Variables & Respondents in this study \\
\hline Somatization factor & $1.49 \pm 0.81$ \\
Obsession-Compulsive factor & $1.84 \pm 1.04$ \\
\hline Interpersonal sensitivity factor & $1.86 \pm 1.01$ \\
\hline Depression factor & $1.62 \pm 0.93$ \\
\hline Anxiety factor & $1.61 \pm 0.92$ \\
\hline Hostile factor & $1.57 \pm 0.96$ \\
\hline Phobia factor & $1.68 \pm 0.98$ \\
\hline Paranoid factor & $1.64 \pm 0.94$ \\
\hline Psychotic factor & $1.52 \pm 0.91$ \\
\hline Other factors & $1.63 \pm 0.97$ \\
\hline
\end{tabular}

\section{Discussion}

The emergence of COVID-19, with its rapid spread, has exacerbated anxiety in populations globally, leading to mental health disorders in individuals. This has even caused cases of stereotyping and discrimination (21). Most of the studies which is done previously in this area predominantly focused on the psychological status of patients (22) or medical staffs (21-23) during the epidemic, and little attention has been directed to the psychological status and behavior changes of the general public. Therefore, it is necessary to examine and recognize people's mental states in this challenging, destructive and unprecedented time. Recent studies have similarly shown that COVID-19 affects mental health outcomes such as anxiety, depression, and post-traumatic stress symptoms $(8,24,25)$. COVID-19 is novel and unexplored, and its rapid transmission, its high mortality rate, and concerns about the future can be the causes of anxiety, depression and other psychological abnormalities (26). Anxiety, when above normal, weakens body's immune system and consequently increases the risk of contracting the virus (27). 
Our study found that ratio of overall state anxiety among respondents was $46.7 \%$, which was greater than that of trait anxiety, suggesting that the epidemic had caused some anxiety. Similarly, significant number of participates were prone to depression (37.2\%) and psychological abnormalities (27.4\%). This result is consistence with the study done in China (6). In our study, females appeared to be more prone to anxiety, depression and other psychological abnormalities than male. This may be due to their sensitivity to psychological stress and post-traumatic stress disorder than men (6). This result also consistent with other studies done in China $(19,26,27)$, Iran (28).

Aging increases the risk of COVID-19 infection and mortality, however, the results of existing studies show that during the pandemic, the levels of anxiety, depression and psychological abnormalities are significantly higher in the age group of 19-39 years. The main reason for this seems to be that this age group, as they are key active working forces in a society, have the main responsibility for social productivity and their family, so they concerned over the future consequences and economic challenges caused by the pandemic, therefore, mostly affected by redundancies and business closures $(19,25,28,29)$. Some researchers have argued that a greater anxiety among young people may be due to their greater access to information through social media, which can also cause stress $(19,28)$.

Our study result indicated that, people with higher level of education had greater level of anxiety, depression and psychological abnormalities. Consistently, the recent studies done in Iran (28) and China (30) indicated that there is an association between education level and anxiety and depression. This may be due to, even if the public had equal chance to be infected by COVID-19, this group's high self-awareness in relation to their own health (31).

Those study participants who were single in their marital status had high level state anxiety, trait anxiety, depression and psychological abnormalities. This may be due to lack of close interpersonal relationship with others. There were no significant difference in state anxiety, trait anxiety, depression and psychological abnormalities in the place where the participants lives (sub-city).

Participants who are working at government institutes had high level state anxiety, trait anxiety, and depression. This may be due to living expense and market inflation caused by COVID-19. Similarly, significant number of the study participants who are working at private company had state anxiety, trait anxiety, depression and psychological abnormalities. This may be due to job security, if the epidemic continues with this pace for unlimited time, their job become under question.

We found participants with better knowledge about COVID-19 had more state and trait anxiety, depression and other psychological abnormalities. The reason for this may the public psychological status is more likely worsen, as the knowledge about epidemic situation and number of confirmed cases and deaths from COVID-19 increased. Most of the news published on COVID-19 are distressing, and sometimes news are associated with rumors, which is why anxiety levels rise when a person is constantly exposed to COVID-19 news. Misinformation and fabricated reports about COVID-19 can exacerbate anxiety and depressive symptoms in the general population (32).

Participants who worried much about infected with COVID-19 had high level of state anxiety, trait anxiety, depression and psychological abnormalities. The main reason for this seems to be time to time and day to day increasing number of patients, suspected cases and death, as well as the increased number of countries affected by the outbreak (33).

About $80 \%$ of the study participants life or/and work were affected by the epidemic. And those participants were also prone to high level of state anxiety, trait anxiety, depression and psychological abnormalities. Consistent with our study result, the study done on Chinese college students during epidemic indicated that COVID-19 related stressors, which includes economic stressors, effects on daily-life, and academic delays, were positively associated with anxiety and depression (33). In addition to the national health situation, the epidemic will also have a significant impact on the economy of the country and individuals. Because of the outbreak, some families will lose their source of income, which inevitably disrupted routine life of the study participants and resulted anxiety and depression.

From the perspective of the severity of psychological symptoms, factors that scored 2 or higher in the SCL-90 were Obsession-Compulsive (OC) factor and Interpersonal sensitivity factor relatively presenting with more severe symptoms. Obsession is a mental illness that causes repeated unwanted thoughts or sensations (obsessions) or the urge to do something over and over again (compulsions) (34). Obsessions are characterized as persistent, unintentional, and unwanted thoughts and urges that are highly intrusive, unpleasant, and distressing (35). Therefore, due to the COVID epidemic, relatively significant number of the study participants experience recurrent, persistent thoughts, impulses, and urges that lead them to depression or anxiety.

\section{Limitations}

Some methodological limitations should be considered when interpreting the result of this study. First, we used cross sectional study design, which could reflect the psychological status of the population at a single time point, which might not reflect long-term exposure to the dimensions related to participants' psychological health when facing the COVID-19 epidemic. Second, the study population is based on voluntary selection, which might introduce a selfselection bias. The third limitation was that we used self-reporting data collection materials; there is no guarantee that the questionnaire responses were not distorted. Notwithstanding the above limitations, this study provides valuable information on the psychological status of the population.

\section{Conclusion And Recommendation}

In less than few months, the COVID-19 pandemic has created an emergency state globally. This contagious virus has not only raised concerns over general public health, but has also caused a number of psychological disorders like anxiety, depression and other psychological abnormalities. According to our study analysis, it can be conclude that Addis Ababa dwellers are experiencing anxiety, depression and other psychological abnormalities due to COVID-19 pandemic. The government, health officials and other stakeholders needs to pay more attentions to the psychological status of the public, especially those 
aged 19-39 years. This age group appears likely to experience psychological stress when faced with an infectious disease epidemic like COVID-19. Even if there is inconsistency and improper implementation of prevention measures, majority of the participants fallow specific behaviors required to prevent and control the epidemic, but it will take time to observe the effect of these behaviors on the epidemic. We hope that this preliminary survey can provide some guidance for psychological interventions for the Addis Ababa dwellers and for Ethiopian population in general and it can serve as a base line for further researches.

Based on the public psychological status during the COVID-19 epidemic, we suggest that government and health officials must provide the latest and more accurate information on the state of the pandemic, refute rumors in a timely manner, and reduce the impact of misinformation on the general public's emotional state can reduce anxiety, depression and psychological abnormalities levels. Optimistic and positive thoughts and attitude toward the COVID-19 spread are also protective factors against depression and anxiety (32). In this regards, mental health professionals recommended promoting healthy behaviors, avoiding exposure to negative news, and using alternatives communication methods such as social networks and digital communication platform to prevent social isolation.

Doing broad based researches with the aim of monitor and report rates of anxiety, depression, and psychological abnormalities both to understand mechanisms and crucially to inform interventions is so important. This should be adopted across the general population and vulnerable groups, including front-line workers. The surveyed medical doctors also recommend that, government should provide necessary personal prevention equipment (PPE) like N95 or surgical mask, surgical gloves and other materials which help the health personnel to protect them from being infected by COVID-19. Individuals also, instead of being afraid and panic about the current situation, it is better to be more conscious and implement specific instructions given from government and other responsible bodies.

\section{Abbreviations}

COVID-19: The outbreak of coronavirus disease-19; SCL-90: Symptom Checklist-90; STAI: State-Trait Anxiety Inventory; SDS: Self-rating Depression Scale; ECA: Africa Economic Commission; OC: Obsessive-compulsive; WHO: World Health Organization

\section{Declarations}

\section{Acknowledgements;}

We would like to thank authorities of Kotebe Metropolitan University for the scientific and ethical approval and financial support of this research. We also sincerely thank all participants who participated in this study.

\section{Authors' contributions}

FT, RW, YC and MD: study concept and design, acquisition of the data, analysis and interpretation of the data, and drafting of the manuscript, acquisition of the data, critical revision of the manuscript for important intellectual content, analysis and interpretation of the data, drafting of the manuscript, and statistical analysis, study supervision. The author(s) read and approved the final manuscript.

\section{Funding}

The authors received financial support from the Kotebe Metropolitan University. The funder had no role in the study design, data collection and analysis or manuscript production.

\section{Availability of data and materials}

Datasets are available through the corresponding author upon request.

\section{Ethics approval and consent to participate}

This study was approved by the ethics committee of Kotebe Metropolitan University. The informed written consent was obtained from all participants.

\section{Consent for publication}

All authors have read through the final version of the manuscript and given consent for publication in BMC Psychology

\section{Competing interests}

All authors of this manuscript have no financial or non-financial conflicts of interest to declare

\section{Author details}

${ }^{1}$ Kotebe Metropolitan University, Minilik II Medical \& Health Science College. ${ }^{2}$ Technology and Innovation Institute.

\section{References}


1. Saleem S, Ahmad Khan I, Saleem T. Anxiety and Emotional Regulation;Anxiety and Emotional Regulation among Pupils of a State- Owned Medical Institution: A Gender Perspective. Prof Med J. 2019;26(05):734-41.

2. TheyDiffwe.com. Difference between State and Trait Anxiety [Internet]. 2017. Available from: https://theydiffer.com/difference-between-state-and-traitanxiety/\#: :text=State anxiety can be seen as a temporary,and lower among middle and upper class individuals

3. Layer, K.; Khan Z. Depression - A Review. Res J Recent Sci. 2012;1(4):79-87.

4. WHO. Depression [Internet]. 2020. Available from: https://www.who.int/news-room/fact-sheets/detail/depression

5. Fardin MA. Covid-19 and anxiety: A review of psychological impacts of infectious disease outbreaks. Arch Clin Infect Dis. 2020;15(COVID-19):11-3.

6. Liu X, Luo WT, Li Y, Li CN, Hong ZS, Chen HL, et al. Psychological status and behavior changes of the public during the COVID-19 epidemic in China. Infect Dis Poverty. 2020;9(1):1-11.

7. Saadatian-Elahi M, Facy F, Del Signore C, Vanhems P. Perception of epidemic's related anxiety in the General French Population: A cross-sectional study in the Rhne-Alpes region. BMC Public Health. 2010;10.

8. Hawryluck L, Gold WL, Robinson S, Pogorski S, Galea S, Styra R. SARS control and psychological effects of quarantine, Toronto, Canada. Emerg Infect Dis. 2004;10(7):1206-12.

9. Wang C, Pan R, Wan X, Tan Y, Xu L, Ho CS, et al. Immediate Psychological Responses and Associated Factors during the Initial Stage of the 2019 Coronavirus Disease (COVID-19) Epidemic among the General Population in China. Int J Environ Res Public Health. 2020;113(5):311-2.

10. Chang J, Yuan Y, Wang D. Mental health status and its influencing factors among college students during the epidemic of COVID-19. J South Med Univ. 2020;40(2):171-6.

11. Spielberger CD, Gorsuch RL LR. STAI Manual. Consulting Psychologists Press. 1970.

12. WHO. The Zung Self-Rating Depression Scale [Internet]. 2020. Available from: https://www.who.int/substance_abuse/research_tools/zungdepressionscale/en/

13. Derogatis LR. Symptom Checklist-90-Revised. 1994.

14. SIDA. Structures and Relations of Power in Ethiopia [Internet]. 2003. Available from:

https://www.sida.se/contentassets/c77ce976b22f4b409c0b9d67c8d3530c/structures-and-relations-of-power-in-ethiopia_469.pdf

15. Central Statistical Agency. Population Projection of Ethiopia for All Regions At Wereda Level from 2014 - 2017 [Internet]. 2013. Available from: http://www.csa.gov.et/images/general/news/pop_pro_wer_2014-2017_final

16. Baker S. Addis Ababa [Internet]. ethiogrio. 2012. Available from: https://www.ethiogrio.com/site/mobile/mobile/articles/3174-addis-ababa.html

17. Masters NB, Tefera YA, Wagner AL, Boulton ML. Vaccine hesitancy among caregivers and association with childhood vaccination timeliness in Addis Ababa, Ethiopia. Hum Vaccines Immunother [Internet]. 2018;14(10):2340-7. Available from: https://doi.org/10.1080/21645515.2018.1480242

18. United Nations. One UN Assessment: Socio-Economic Impact of COVID-19 in Ethiopia. 2020.

19. Hatfield R. Difference Between State and Trait Anxiety [Internet]. livestrong. 2020. Available from: http://www.livestrong.com/article/98672-differencesbetween-state-anxiety-/

20. Holi M. Assessment of psychiatric symptoms using the SCL-90. 2003. 82 p.

21. Lima CKT, Carvalho PM de M, Lima I de AAS, Nunes JVA de O, Saraiva JS, de Souza RI, et al. The emotional impact of Coronavirus 2019-nCoV (new Coronavirus disease). Psychiatry Res [Internet]. 2020;287:112915. Available from: https://doi.org/10.1016/j.psychres.2020.112915

22. CHENG SKW, WONG CW, TSANG J, WONG KC. Psychological distress and negative appraisals in survivors of severe acute respiratory syndrome (SARS). Psychol Med. 2004;34(7):1187-95.

23. McAlonan GM, Lee AM, Cheung V, Cheung C, Tsang KWT, Sham PC, et al. Immediate and sustained psychological impact of an emerging infectious disease outbreak on health care workers. Can J Psychiatry. 2007;52(4):241-7.

24. Maunder RG, Lancee WJ, Balderson KE, Bennett JP, Borgundvaag B, Evans S, et al. Long-term psychological and occupational effects of providing hospital healthcare during SARS outbreak. Emerg Infect Dis. 2006;12(12):1924-32.

25. Maunder R. The experience of the 2003 SARS outbreak as a traumatic stress among frontline healthcare workers in Toronto: Lessons learned. Philos Trans R Soc B Biol Sci. 2004;359(1447):1117-25.

26. Banerjee D. The COVID-19 outbreak: Crucial role the psychiatrists can play. Asian J Psychiatr. 2020;50(102014).

27. WHO. Mental Health and Psychosocial Considerations During COVID-19 Outbreak. World Heal Organ [Internet]. 2020;(January):1-6. Available from: file:///C:/Users/muled/Downloads/COVID referances/Mental health and psychosocial considerations during the.pdf

28. Moghanibashi-Mansourieh A. Assessing the anxiety level of Iranian general population during COVID-19 outbreak. Asian J Psychiatr [Internet]. 2020;51(April):102076. Available from: https://doi.org/10.1016/j.ajp.2020.102076

29. Liu D, Ren Y, Yan F, Li Y, Xu X, Yu X, et al. Psychological Impact and Predisposing Factors of the Coronavirus Disease 2019 (COVID-19) Pandemic on General Public in China. SSRN Electron J. 2020;2019.

30. Wang Y, Di Y, Ye J, Wei W. Study on the public psychological states and its related factors during the outbreak of coronavirus disease 2019 (COVID-19) in some regions of China. Psychol Heal Med. 2020;8506.

31. Zhang Y, Ma ZF. Impact of the COVID-19 pandemic on mental health and quality of life among local residents in Liaoning Province, China: A crosssectional study. Int J Environ Res Public Health. 2020;17(7).

32. Zhou SJ, Zhang LG, Wang LL, Guo ZC, Wang JQ, Chen JC, et al. Prevalence and socio-demographic correlates of psychological health problems in Chinese adolescents during the outbreak of COVID-19. Eur Child Adolesc Psychiatry [Internet]. 2020;29(6):749-58. Available from:

Page $12 / 13$ 
https://doi.org/10.1007/s00787-020-01541-4

33. Cao W, Fang Z, Hou G, Han M, Xu X, Dong J, et al. The psychological impact of the COVID-19 epidemic on college students in China. Psychiatry Res [Internet]. 2020;287(March):112934. Available from: https://doi.org/10.1016/j.psychres.2020.112934

34. Burroughs E, Kitchen RPK, Sandhu V, Peggy F, Richter M. Obsessive Compulsive Disorders: A Handbook for Patients and Families [Internet]. 2015. Available from: https://sunnybrook.ca/uploads/1/departments/psychiatry/ocd-information-guide-2015.pdf

35. Rosie M. Spielman. Psychology. 2014.

\section{Figures}

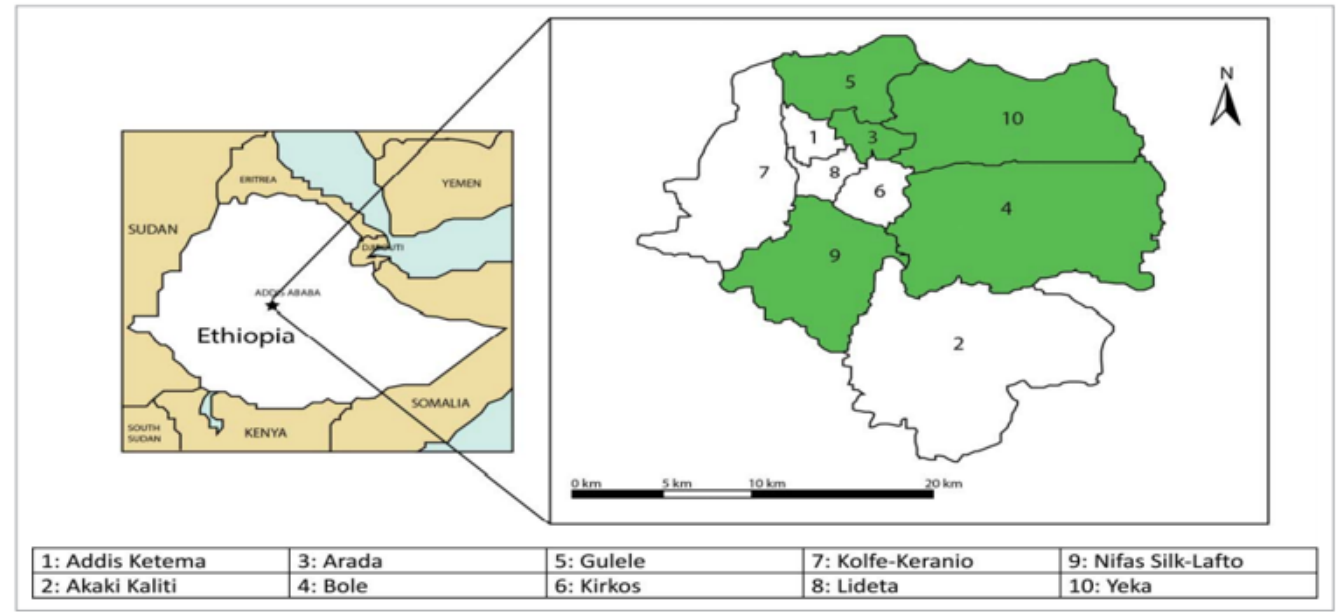

\section{Figure 1}

Map of Addis Ababa with administrative sub-city designations. Modifided from (17). Note: Highlighted sub-cities (Arada, Gulele, Yeka, Bole, and Nifas Silk) were selected randomly as clusters for analysis 